\title{
Directional selection on body weight and hybrid dysgenesis in Drosophila melanogaster
}

\author{
D Higuet \\ Université P\& M Curie, Laboratoire de Génétique des Populations, \\ Mécanismes Moléculaires de la Spéciation, Tour 42, 4e étage, 4 place Jussieu, \\ 75251 Paris, France
}

(Received 9 October 1990; accepted 20 March 1991)

\begin{abstract}
Summary - The influence of transposable elements in generating variation for body weight of Drosophila melanogaster was investigated by comparing the response to artificial divergent selection in dysgenic and nondysgenic crosses using 2 independent systems of hybrid dysgenesis (PM and IR). Two replicates of initially dysgenic or nondysgenic crosses between Furnace Creek (IP) and Gruta (RM) strains were selected for increased and decreased body weight during 13 generations. A greater divergence in selection response was observed for the dysgenic lines than for the nondysgenic lines, but this difference disappeared when selection was relaxed. The selected lines were analysed at generation 13 with respect to their dysgenesis properties, as well as to the number and nature of their $\mathrm{P}$ and I elements. There was no correlation between the characteristics of the $\mathrm{P}$ and $\mathrm{I}$ elements in the selected lines and the intensity of response to selection for body weight. In both types of crosses, hybrid dysgenesis induced modification in body weight variance, probably by I and P-induced mutations.
\end{abstract}

hybrid dysgenesis / PM and IR systems / body weight / Drosophila melanogaster

Résumé - Sélection directionnelle sur le poids des adultes et dysgénèse des hybrides chez Drosophila melanogaster. L'aptitude des éléments transposables à générer de la variabilité pour le caractère poids des adultes chez Drosophila melanogaster, et donnant ainsi une plus grande prise à la sélection, a été étudiée en comparant la réponse à une sélection bidirectionnelle suivant que le croisement originel était ou non dysgénique vis$\grave{a}$-vis des systèmes PM et IR de dysgénèse des hybrides. Deux répliques de chaque type de croisement (dysgénique ou non dysgénique) ont été réalisées entre les souches Furnace Creek (IP) et Gruta (RM), puis une sélection bidirectionnelle a été appliquée pour un poids élevé des adulles ou pour un poids faible. Une plus grande divergence de réponse à la sélection a été observée lorsque le croisement initial était dysgénique par rapport au cas où il était non dysgénique. Mais cette différence disparaît quand la pression de sélection est relâchée. En fin de sélection (génération 13), les lignées sélectionnées ont été analysées pour le nombre et la nature de leurs éléments $P$ et I. Aucune corrélation n'a été mise en évidence entre les caractéristiques des éléments $P$ et I présents dans les lignées sélectionnées et l'intensité de la réponse à la sélection. Dans les 2 types de croisements, 
la dysgénèse des hybrides induit des modifications de la variance du poids des adultes, probablement dues à des mutations induites par les éléments transposables.

dysgénèse des hybrides / systèmes PM et IR / poids des adultes / Drosophila melanogaster

\section{INTRODUCTION}

The discovery of transposable elements in the Drosophila genome has breathed new life into population genetics. Transposable elements may modify the organisation of the genome by mediating deletions, translocations, transpositions, duplications and inversions, and are thus a source of genetic innovation. Whilst the mechanisms involved in transposition are beginning to be understood, the effect of transposable element mobility on generating variation for quantitative traits remains unclear. Both Gvozdev et al (1981) and Mackay (1984, 1985), using the mdg-1 mobile element and $\mathrm{P}$ elements respectively, have shown that transposable elements can contribute to selection response. This may occur either through preferential insertion (Gvozdev et al, 1981), or as transposable element-induced variability which permits a greater selection response (Mackay, 1984, 1985). However, the observation of greater selection response from dysgenic than from nondysgenic crosses has not been repeated (Morton and Hall, 1985; Torkamanzehi et al, 1988; Pignatelli and Mackay, 1989). In parallel, several experiments were performed to ascertain the effect of transposable elements on fitness (for review see Mackay, 1989) or the ability of the PM hybrid dysgenesis system to generate mutations on the $\mathrm{X}$ chromosome that would affect bristle traits (Lai and Mackay, 1990).

In this report, observations on the response to selection from dysgenic and nondysgenic crosses (for both P-M and I-R systems) are extended to another quantitative trait (body weight). After selection ceased, the relationship between the response attained and the transposition of $\mathrm{P}$ and I elements was investigated.

Two independent systems of hybrid dysgenesis associated with $\mathrm{P}$ and I transposable elements (the P-M and I-R systems, respectively) have been described in Drosophila melanogaster (see Engels, 1988; and Finnegan, 1989, for reviews). Dysgenesis is due to incompatibility between chromosomal determinants ( $\mathrm{I}$ or $\mathrm{P}$ elements) and extrachromosomal state, defined as reactivity in the I-R system and as susceptibility in the P-M system. When males of Drosophila melanogaster carrying autonomous $\mathrm{P}$ elements on their chromosomes ( $\mathrm{P}$ males) are crossed to females lacking $P$ sequences ( $M$ females), or carrying defective $P$ elements ( $M^{\prime}$ females), the dysgenesis syndrome can be observed. This takes the form of transposition in the germ line of the dysgenic hybrids and, in both sexes, may lead to gonadal atrophy (GD sterility; Engels, 1983). Also involved in the syndrome are an increase in the level of mutation, male recombination and chromosomal breaks and rearrangements. If males bearing active I elements (I factor) are crossed to females lacking these elements ( $R$ females), the $I$ factors transpose and the F1 females may become sterile due to the death of their progeny at the embryonic stage (SF sterility; Bregliano and Kidwell, 1983). In both systems, the reciprocal cross is nondysgenic. 


\section{MATERIALS AND METHODS}

\section{Strains}

The Furnace Creek strain (captured in California, USA in 1981) is a weak P strain (27\% GD sterility by diagnostic cross A) and an inducer strain with regard to the IR system. The Gruta strain (captured in Argentina in 1950) is an MR strain, as are most old laboratory strains. The Canton-S and Harwich strains are $\mathrm{M}$ and $\mathrm{P}$ type reference strains, respectively (Kidwell et al, 1977).

\section{Selection}

The trait selected was the weight of 2-d-old adults since Drosophila attains its maximum weight in 2 days. Cultures were maintained at a constant temperature of $25^{\circ} \mathrm{C}$, with 12 -h photoperiod, on medium without live yeast (David, 1959). This medium was chosen because it gave good repeatability of weight measures.

Dysgenic D $(30 \mathrm{MR} \times 30 \mathrm{PI})$ and nondysgenic ND $(30 \mathrm{PI} \times$ $30 \mathrm{MR}$ ) crosses were set up between Furnace Creek and Gruta. In the following generation (G0), mass selection was carried out for increased (H) and decreased (L) body weight with proportion 15/60 of each sex in each replicate and direction of selection. The measured individuals were chosen randomly among the earliest to eclose. Selection was continued for 13 generations. In each line, selection was relaxed for 10 generations starting at generation 14, and body weight was scored after 5 (G18) and 10 (G23) generations of relaxation. All selected lines were kept contemporary. Two days after the beginning of the experiment, a replicate of it was performed. The selected lines of the first replicate were denoted 1 and these of the second were denoted 2. At the end of the selection period (generation 13), each selected line was studied with regard to the P-M and I-R systems.

\section{$P$ susceptibility determination}

Standard diagnostic tests based on measuring gonadal (GD) sterility potential (Kidwell et al, 1988) were used. Thirty virgin females from each selected line were crossed to Harwich males and their offspring were raised at $29^{\circ} \mathrm{C}$ (cross $\mathrm{A}^{*}$ ), a temperature which is restrictive for gonadal sterility in the P-M system. GD sterility was measured as follows : $50 \mathrm{~F} 1$ females (2-d-old) were dissected and their ovaries were examined. Dysgenic ovaries were scored and the frequency was calculated $\left(\mathrm{GD}\left(\mathrm{A}^{*}\right)\right.$ sterility).

\section{$P$ activity determination}

\section{P-induced GD sterility}

Thirty males from each selected line were crossed to 30 virgin Canton-S females (cross A). The percentage of dysgenic ovaries was calculated by dissection of $50 \mathrm{~F} 1$ females raised at $29^{\circ} \mathrm{C}(\mathrm{GD}(\mathrm{A})$ sterility). 


\section{Hypermutability of the $\mathbf{P}\left(w^{d 1}\right) 9.3$ composite transposon}

The $\mathrm{P}\left(w^{d 1}\right) 9.3$ is a composite transposon which carries the white gene as a selectable marker, inserted within a defective $P$ element. It can be mobilized in trans by a complete $\mathrm{P}$ element (Coen, 1990). Forty males from cach selected line were crossed to 40 females of the $w^{1118} P\left(w^{d 1}\right) 9.3$ strain at $20^{\circ} \mathrm{C}$. This $\mathrm{M}$ strain possesses a deletion at the white locus and has been transformed by the composite transposon $\mathrm{P}\left(w^{d 1}\right) 9.3$, which is located at $19 \mathrm{DE}$ on the $\mathrm{X}$ chromosome. At the following generation, 40 males were individually crossed to attached-X females lacking $\mathrm{P}$ elements. The male progeny were screened for eye color mutants (non-wild males). Hypermutability was estimated by the mutation rate per gamete, calculated as the weighted average number of mutants per male. Its variance was calculated following the method of Engels (1979).

\section{Molecular analysis}

\section{In situ hybridization}

The number of $\mathrm{P}$ and I elements in each selected line was determined by in situ hybridization. Polytene chromosomes from salivary glands were prepared by the method described by Pardue and Gall (1975), revised by Strobel et al (1979). Nicktranslated $p \pi 25.1$ plasmid DNA (O'Hare and Rubin, 1983) and $p I 407$ plasmid DNA (Bucheton et al, 1984) were used as probes. For each selected line, 2 or 3 slides were studied and a minimum of 4 nuclei per slide were examined.

\section{Southern blots}

The structure of $\mathrm{P}$ elements in each selected line was analysed using the Southern blot method. Genomic DNA was extracted using the method described by Junaković et al (1984). Restriction enzyme digestion of about $3 \mu \mathrm{g}$ of DNA was performed according to the supplier's instructions. After gel electrophoresis, transfers were carried out on nylon filters (Biodyne, Pall) which were submitted to hybridization. The filters were hybridized as recommended by the suppliers and autoradiographed using Kodak XAR film. The Southern blots were hybridized with nick-translated almost complete $\mathrm{P}$ element from the $p \pi 25.7 \mathrm{BWC}$ clone (O'Hare, personal communication).

\section{RESULTS}

\section{Response to selection}

The evolution of the mean and the variance of body weight in each sex is shown in figures 1 and 2, respectively, for the dysgenic and nondysgenic selected lines. For both sexes, a larger average divergence between lines selected in opposite directions was observed when the original cross was dysgenic, as shown by the corresponding analyses of variance (table I). However, the phenotypic variance of the lines (dysgenic and nondysgenic) did not substantially change in the course of the experiment. 
Dysgenesis and body weight selection
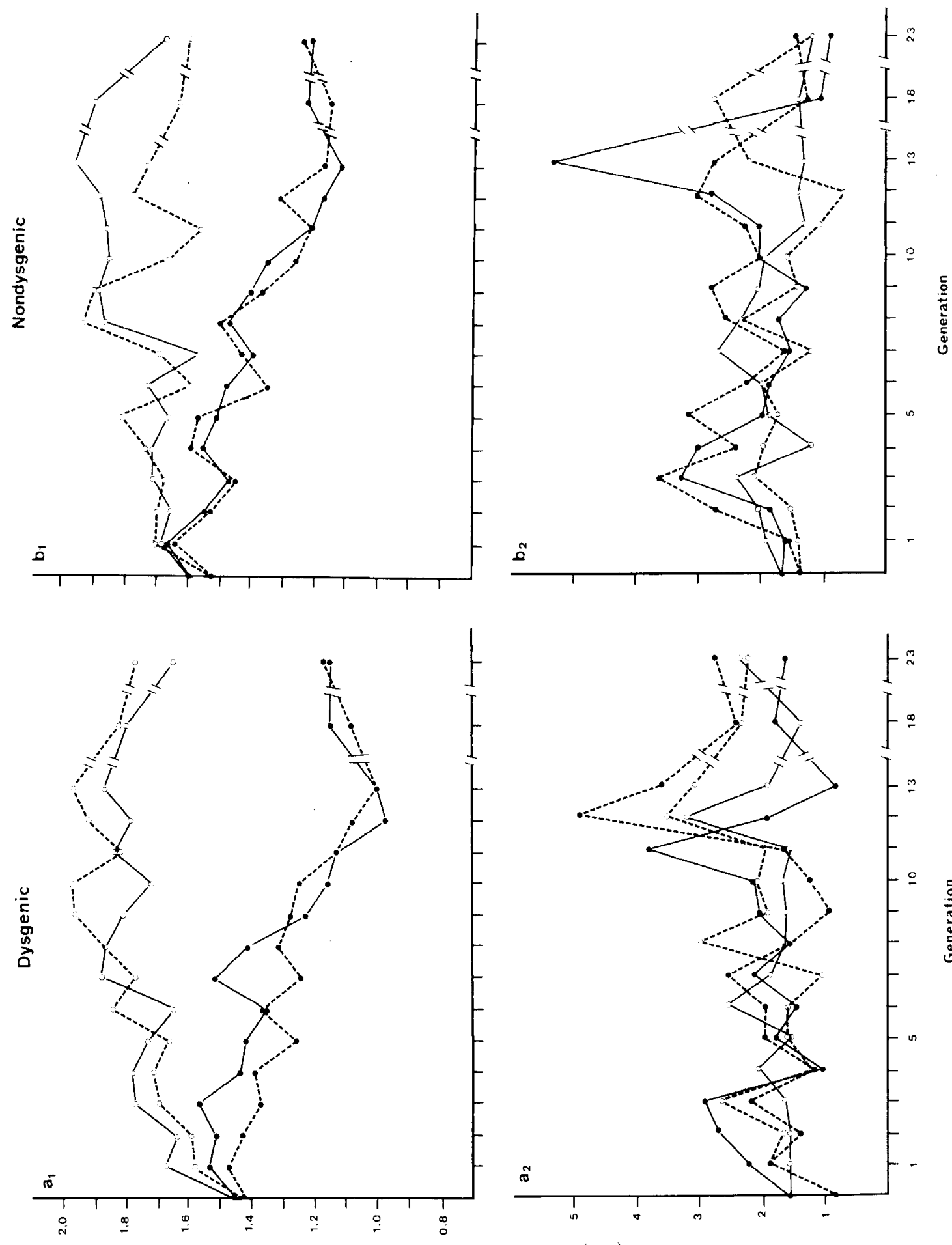

(6ui) 146 !am kpoq ueaw

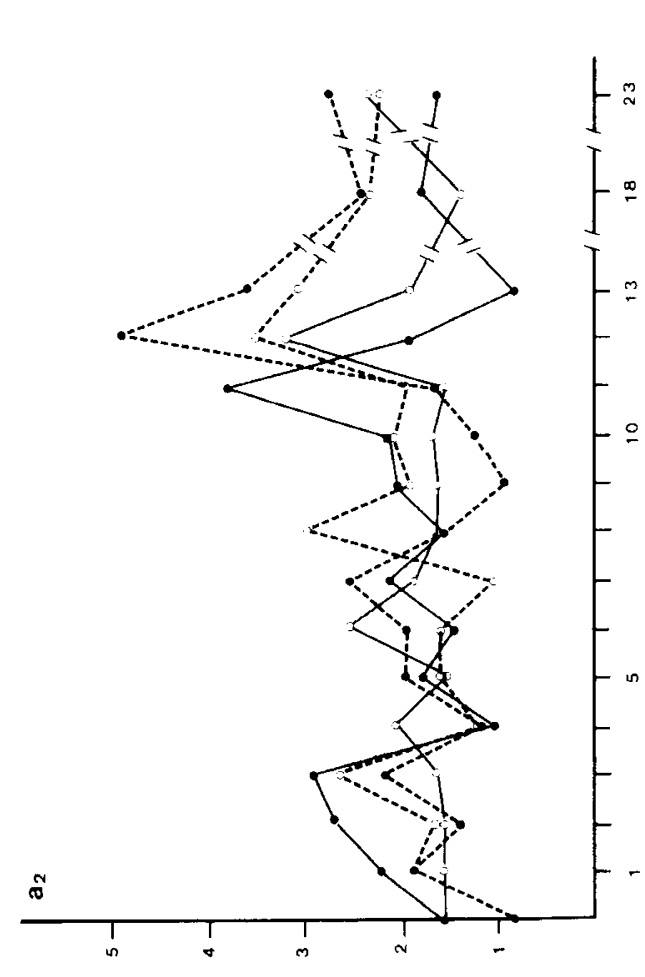

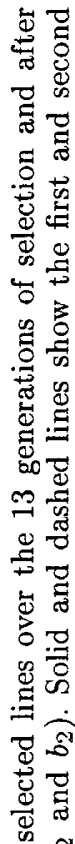

.

-

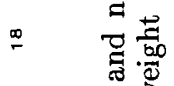

$=$.

60

केष

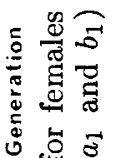

赵

.

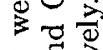

$\rightarrow$

$\therefore \frac{\infty}{1}$

퓨유.

$\sum$ हี क

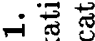

$\stackrel{\infty}{\infty}$

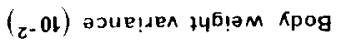



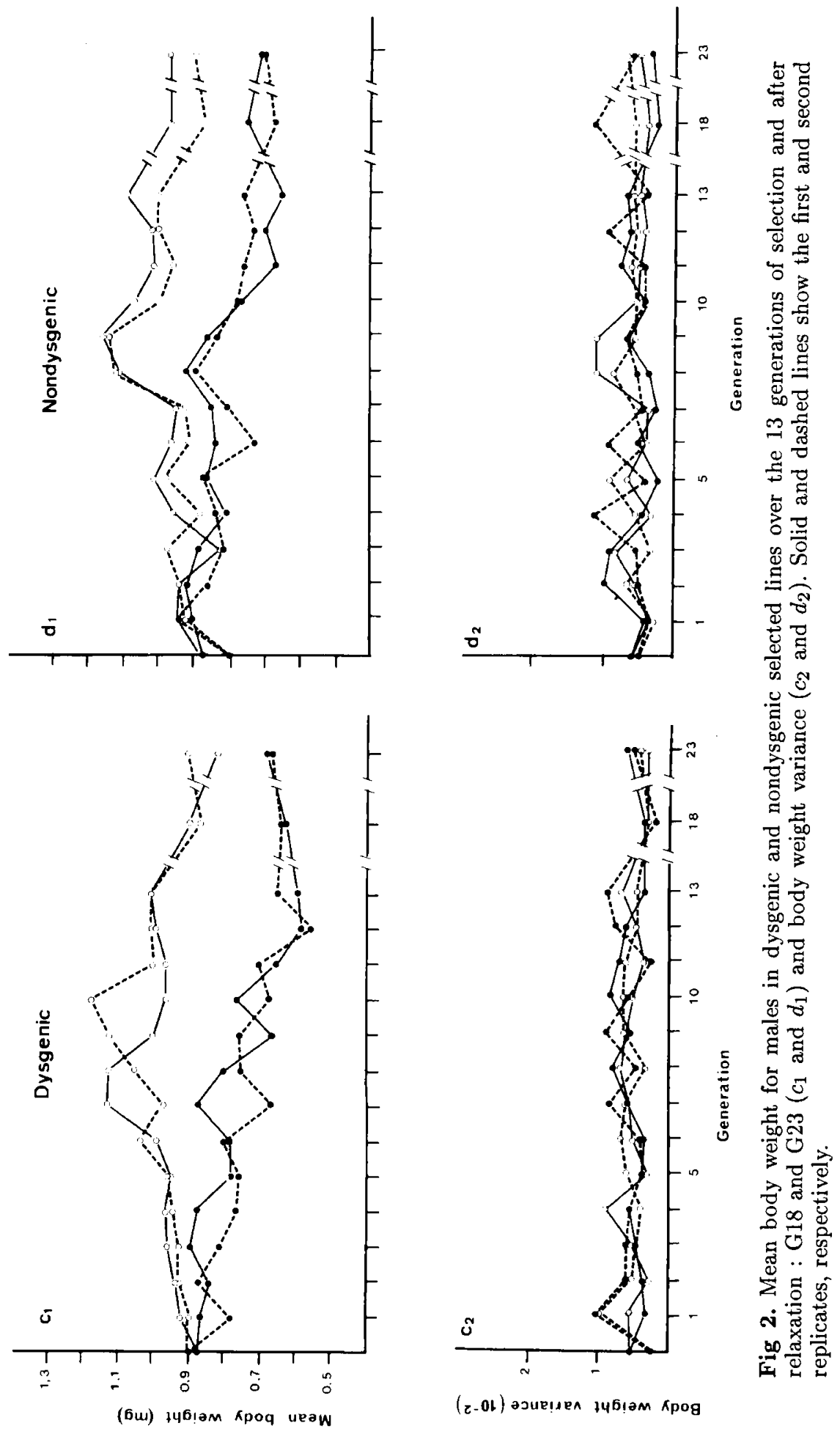
Table I. Analysis of variance of the divergence between heavy and light lines (I), over 13 generations of selection in both sexes; (II), after relaxation of selection, the last generation of selection included (G13, G18 and G23).

\begin{tabular}{|c|c|c|c|c|c|}
\hline \multirow[b]{2}{*}{ Source of variation } & \multirow[b]{2}{*}{$d f$} & \multicolumn{2}{|l|}{ Females } & \multicolumn{2}{|l|}{ Males } \\
\hline & & Mean square & $\mathrm{F}$ & Mean square & $\mathrm{F}$ \\
\hline Original cross & 1 & 0.2910 & $31.94^{* * *}$ & 0.0680 & $13.04^{* *}$ \\
\hline Generation & 12 & 0.1961 & $21.52^{* * *}$ & 0.0547 & $10.50^{* * *}$ \\
\hline Interaction & 12 & 0.0059 & 0.65 & 0.0019 & 0.36 \\
\hline Error & 26 & 0.0091 & & 0.0052 & \\
\hline
\end{tabular}

II. After relaxation (G13, G18 and G23)

Females

Males

\begin{tabular}{lcccccc}
\cline { 6 - 6 } \cline { 6 - 7 } Source of variation & $d f$ & Mean square & $\mathrm{F}$ & & Mean square & $\mathrm{F}$ \\
\hline Original cross & 1 & 0.0901 & 4.86 & & 0.0008 & 0.18 \\
Generation & 2 & 0.0946 & 5.10 & & 0.0281 & $6.10^{*}$ \\
Interaction & 2 & 0.0071 & 0.38 & & 0.0029 & 0.62 \\
Error & 6 & 0.0185 & & & 0.0046 & \\
\hline
\end{tabular}

${ }^{*} P<0.05 ;{ }^{* *} P<0.01 ;{ }^{* * *} P<0.001$.

For each pair of divergent selection lines, the average response $(m)$ per generation of selection was estimated by the regression coefficient of the mean on generation number, and the observed response to selection $(R o)$ was estimated as $12 \mathrm{~m}$. The expected response to selection $\left(R e_{13}\right)$ and its variance $V(R e)$ were estimated following the method described by Pignatelli and Mackay (1989). The expected response to selection per generation is the standard $R e=i h^{2}(V p)^{1 / 2}$ (Falconer, 1981), where $i$ is 1.3 for 15 selected from 60 of each sex, $h^{2}$ and $V p$ are the realized heritability and the phenotypic variance respectively. Realised heritability $h^{2}$ was estimated for each sex from regression of cumulated response on cumulated selection differential over the 3 first generations (G1 to G3), all replicates and directions of selection were pooled. The mean of the $4 h^{2}$ estimated was the used value. For females and males from dysgenic crosses $h^{2}$ were 0.2153 and 0.0232 , respectively, for females and males from nondysgenic crosses $h^{2}$ were 0.2233 and 0.1410 , respectively. The estimate of phenotypic variance $(V p)$ used for each selected line was that from generation 0 , pooled over the 2 replicates. The predicted cumulated response at generation $13\left(R e_{13}\right)$ is then $12 R e$, assuming $h^{2}$ and $V p$ are constant. The expected variance of response from drift and sampling is approximately : $2 F_{t} V a+\left(V p_{t}-\left(V a_{t} / 2\right)\right) / M$ (Hill, 1977), where $\mathrm{F}_{t}$ is the inbreeding coefficient at time $t, V a$ is the additive genetic variance segregating in the base population, $V p_{t}$ and $V a_{t}$ are the phenotypic and genetic variances, respectively, of a particular selection line at time $t$, and $M$ is the number of individuals scored per line each generation. For lines maintained with 15 pairs of parents per generation, $F_{13}$ is 0.307 , assuming that the effective size is $60 \%$ of the number of parents 
(Crow, 1954). $V a$ was estimated from $h^{2} V p$, and $V p$ and $V a$ were assumed to remain roughly constant over 13 generations, in the absence of mutation.

The results are shown in table II. The mean response per generation of selection $(m)$ is, on average, 1.26 times greater for the dysgenic than for the nondysgenic selection lines. The observed response to selection $(R o)$ is two times greater for the light lines than for the heavy lines in males from dysgenic crosses and in females from nondysgenic crosses. In the other cases the response to selection is symmetrical. These data differ from previous results on selection for body weight (Higuet, 1986), where the response to selection always was greater for upward selection lines. The comparison of the observed response $(R o)$ with the expected response $\left(R e_{13}\right)$ shows that in males from dysgenic crosses the observed response exceeds that expected by a factor of 8 , whereas in males from nondysgenic crosses observed and expected responses agree moderately well. In females the observed and expected responses do not differ excepted in females from the nondysgenic heavy lines where the observed response is, on average two times smaller than that expected. Finally, the variance of observed response is greater than the variance of the expected response and specially in the dysgenic lines (table II).

Relaxation of selection resulted in decreasing the mean body weight of the heavy lines and increasing that of the light lines, for both types of original crosses (dysgenic or nondysgenic). After 10 generations of relaxation the divergences between the heavy line and the light line in the 2 types of original crosses were not significantly different (table I).

These results suggest that some P and I-induced mutations have a deleterious effect on fitness in the homozygotes, as shown by Fitzpatrick and Sved (1986) and by Mackay (1986) and have an effect on body weight, so that heterozygotes would be retained during the selection process.

In order to look for relationships between the response to selection and the transposition of $\mathrm{P}$ and I elements, genetic and molecular analyses of the selected lines were performed at the end of the selection process (G13).

\section{$P$ susceptibility and $P$ activity}

Table III shows the results of $\mathrm{P}$ susceptibility and $\mathrm{P}$ activity analyses carried out at the end of the selection period (G13). There were no differences between the 2 types of original crosses both for $\mathrm{P}$ susceptibility and $\mathrm{P}$ activity, as measured by GD sterility. One line from the original nondysgenic cross is a $\mathrm{M}^{\prime}$ type line (ND2H). This property probably developed during the selection process, due to genetic drift leading to the loss of P-cytotype determinants. The P activity, measured by the hypermutability of the $\mathrm{P}\left(w^{d 1}\right) 9.3$ transposon, has a tendency to be greater in nondysgenic lines than in dysgenic lines. However, the measure of hypermutability does not significantly differ between the 2 original crosses (Mann and Whitney $U$ statistic not significant; $U=3$ ). The $\mathrm{P}$ properties of the selected lines are uncorrelated either with the original cross type or with the direction of selection. A particular result of this analysis is that several selected lines present greater Pinduced GD sterility than the parent Furnace Creek population. This increase of $\mathrm{P}$-induced GD sterility, uncorrelated with the type of original cross or the direction of selection, could be due to genetic drift leading to the selection of autonomous $\mathrm{P}$ elements causing a high level of GD sterility. 


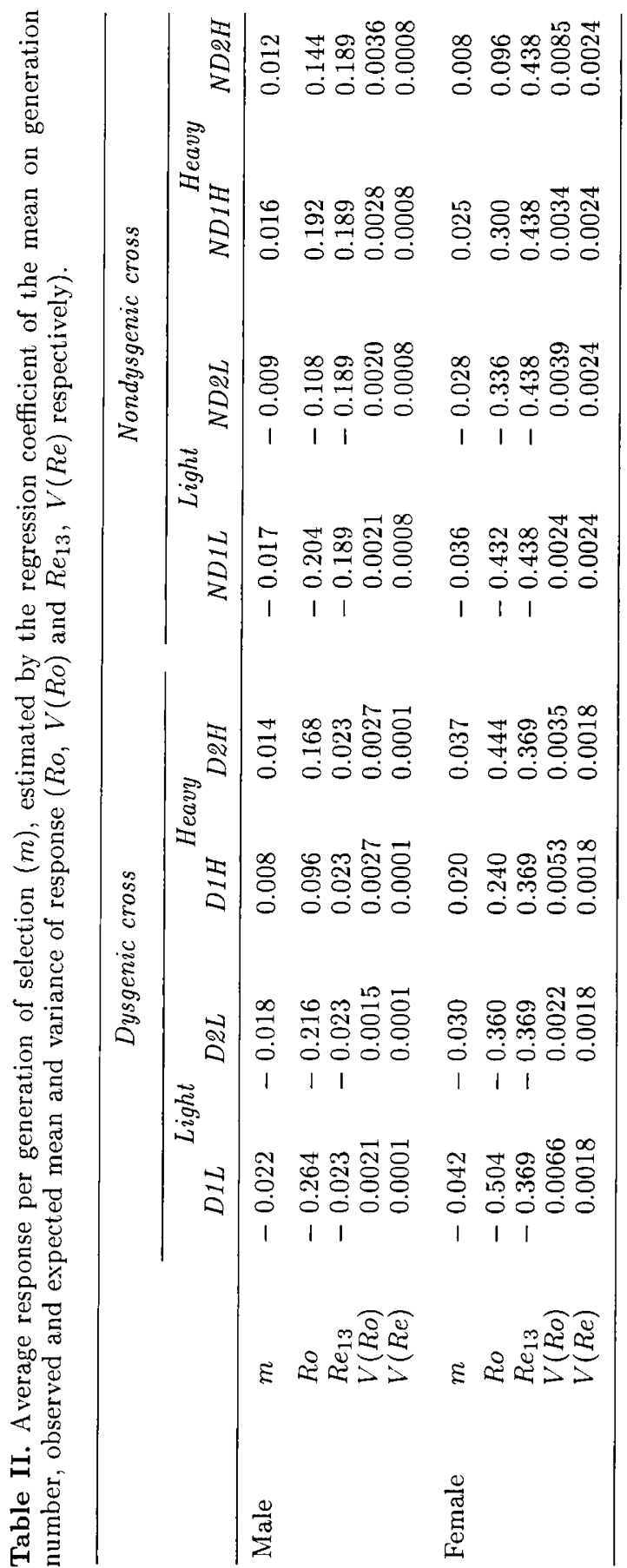




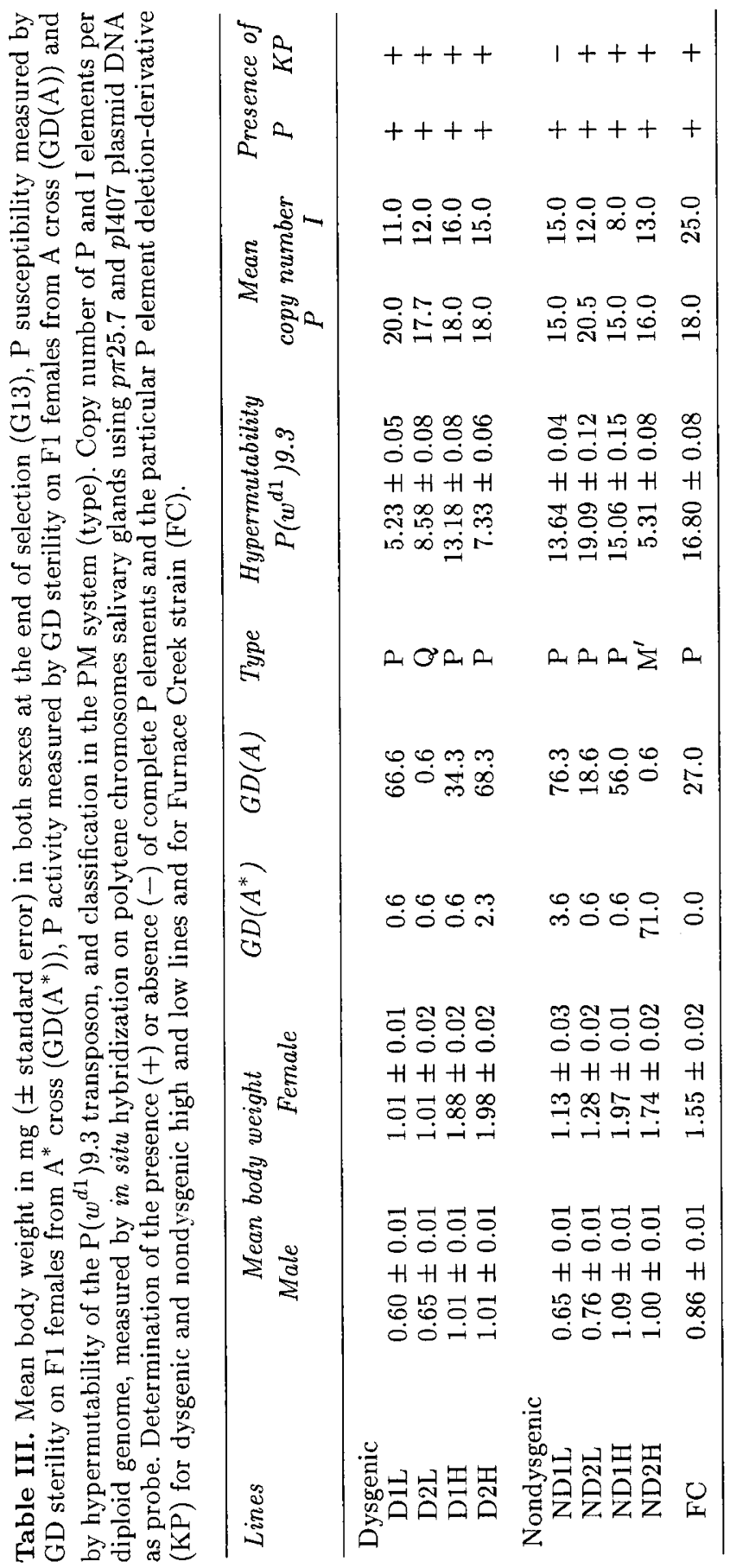


In our experiment hypermutability of the $\mathrm{P}\left(w^{d 1}\right) 9.3$ transposon and ability of $\mathrm{P}$ elements to induce GD sterility are 2 practically independent indicators of hybrid dysgenesis (Spearman's rank correlation $r_{s}=0.02$ ). This result is not surprising, since Kocur et al (1986) and Simmons (1987) suggested that P-induced GD sterility and hypermutability at the $s n$ locus were also uncorrelated.

As expected (Picard, 1976; Pélisson and Brégliano, 1987), all selected lines were found to be inducer lines in the IR system.

\section{Molecular analysis}

In situ hybridization was performed in order to detect transposition, by comparing the sites in the selected lines and the Furnace Creek population. The aim was to find sites associated with selection response. However, this search was unsuccessful. A possible reason for this failure was that the Furnace Creek population was polymorphic for sites of insertion, many of them being at low frequencies. Thus, it will be very difficult to detect transposition events, and to discriminate between drift or selection as causing sites to achieve high frequency. Thereby, only data for the mean copy number of $\mathrm{P}$ and I elements per diploid genome is given for each selected line (table III). No correlation was found between the mean number of transposable elements ( $\mathrm{P}$ or I) and the original cross type or direction or selection.

The presence of complete $\mathrm{P}$ elements (able to produce $\mathrm{P}$-transposase) and of $\mathrm{P}$ element deletion derivatives, in particular the KP element (Black et al, 1988; Boussy et al, 1988) was studied using Southern blot analysis. The KP element has been found to repress $\mathrm{P}$ activity when present at a high frequency (Jackson et al, 1988 ), thus repressing eventual P-induced variability. DNA was digested with the AvaII or DdeI restriction enzymes. Complete $\mathrm{P}$ elements and $\mathrm{KP}$ elements give specific restriction fragments with these two enzymes (Anxolabéhère et al, 1990; Biémont et al, 1990). All selected lines possess the complete $\mathrm{P}$ element and the KP element (table III), except one (ND1L) lacking a KP element. No other particular deletion derivative element was found to be associated with the type of cross or direction of selection.

\section{DISCUSSION}

In our experiment, as in Mackay's experiment (1985), a greater response to selection was found when the original cross was dysgenic than when it was non dysgenic. But in our case the difference between dysgenic and nondysgenic crosses was weaker than previously reported (Mackay, 1985). The response to selection in our dysgenic cross was 1.26 times greater than in the nondysgenic cross when it was twice in Mackay's experiment. Moreover, the phenotypic variances of body weight of the selected lines did not differ between the 2 cross types, in contrast to Mackay's data on abdominal bristle number. It is possible that the reason of this discrepancy could be attributed to the choice of the $\mathrm{P}$ strain. The Furnace Creek strain used in our experiment is a weak $P$ strain (27\% GD sterility by A cross) whilst the Harich strain, used by Mackay, is a strong $\mathrm{P}$ strain (100\% GD sterility by A cross). This difference is correlated to the copy number of $P$ elements : 40 to 50 for Harich, and only 20 for 
Furnace Creek. Thus, transposition rate and its consequence could be greater in Mackay's experiment than in our own.

In our experiment, the response to selection of lines started from the dysgenic cross was larger than that from the nondysgenic. However, the relationship between this result and transposition events remains unclear. Here, as in Mackay's experiments (1985), the difficulty of associating events of transposition and their consequences with the response to selection is due to the experimental method used. Mackay (1986), Torkamanzehi et al (1988), and Pignatelli and Mackay (1989) have inferred that transpositions occur in nondysgenic lines. More recently Shrimpton et al (1990), using in situ hybridization in lines selected for abdominal bristle by Mackay (1985), found no difference in total number of sites per line, mean number of sites per individual, mean copy number per individual, or site frequency, between dysgenic and nondysgenic selected lines, nor between lines selected in opposite directions. Therefore, it is not surprising not to find any difference in the mean copy number of $\mathrm{P}$ and I elements or in the nature of the $\mathrm{P}$ elements between the genomes of selected lines started from the 2 cross types.

Because transpositions and their consequences occur in nondysgenic as well as in dysgenic crosses, the former cannot be used as a control or only in the first generations ( 5 generations after the original cross), after which dysgenic and nondysgenic crosses become similar in regard to the transposition rate. To cope with the problem of control of the transposition, Lai and Mackay (1990) propose a different approach : to determine the ability of the P-M hybrid dysgenesis system to generate mutations affecting bristle number they construct $\mathrm{X}$ chromosome lines in which $\mathrm{X}$ chromosomes were exposed to a dysgenic cross and a nondysgenic cross and recovered in common autosomal backgrounds. They show that dysgenic crosses are 3 times more effective than nondysgenic crosses in inducing polygenic variation. The new variation resulting from one generation of mutagenesis has large effects on bristle score, and all mutations reduced bristle number. Other types of experiments have been performed related to ascertaining the effect of transposable elements on fitness (for review see Mackay, 1989), in particular experiments using a controlled source of transposase.

Finally, another parameter must be considered. Several studies (Williams et al, 1988; Robertson and Engels, 1989; Coen, 1990) imply that repressor-making mutant $\mathrm{P}$ elements affect the expression of $\mathrm{P}$ insertion mutations. Thus the response to selection could be due to P-induced mutations and could be cytotype-dependent owing to the expression of cytotype-dependent $\mathrm{P}$ insertion mutations.

\section{ACKNOWLEDGMENTS}

I wish to thank D Anxolabéhère, JB Bell and C Terzian for their critical reading of the manuscript and anonymous referees for their helpful comments. I thank $\mathrm{C}$ Landré for her technical assistance. This work was supported by Centre National de la Recherche Scientifique (URA 693 : Dynamique du Génome et Evolution) and by the University Pierre et Marie Curie. 


\section{REFERENCES}

Anxolabéhère D, Hu K, Nouaud D, Périquet G (1990) The distribution of the P-M system in Drosophila melanogaster strains from the People's Republic of China. Genet Sel Evol 22, 175-188

Biémont C, Ronsseray S, Anxolabéhère D, Izaabel H, Gautier G (1990) Localization of $\mathrm{P}$ elements, copy number regulation, and cytotype determination in Drosophila melanogaster. Genet Res (Camb) 56, 3-14

Black DM, Jackson MS, Kidwell MG, Dover GA (1988) KP elements repress Pinduced hybrid dysgenesis in $D$ melanogaster. EMBO J 6, 4125-4135

Brégliano JC, Kidwell MG (1983) Hybrid dysgenesis determinants. In : Mobile Genetic Elements (Shapiro JA, ed) Academic Press, NY, 363-410

Boussy IA, Healy MJ, Oakeshott JG, Kidwell MG (1988) Molecular analysis of the P-M gonadal dysgenesis cline in Eastern Australian Drosophila melanogaster. Genetics 119, 889-902

Bucheton A, Paro R, Sang HM, Pelisson A, Finnegan DJ (1984) The molecular basis of I-R hybrid dysgenesis in Drosophila melanogaster : identification, cloning and properties of the I factor. Cell 38, 153-163

Coen D (1990) P element regulatory products enhance zeste ${ }^{1}$ repression of a $\mathrm{P}\left(\right.$ white $\left.^{\text {duplicated }}\right)$ transgene in Drosophila melanogaster. Genetics 126, 949-960

Crow JF (1954) Breeding structure of populations. II. Effective population number. In : Statistics and Mathematics in Biology. Iowa State Coll Press, Ames, IA, 543-556 David JR (1959) Etude quantitative du développement de la Drosophile élevée en milieu axénique. Bull Biol Fr Bel 93, 472-505

Engels WR (1979) The estimation of mutation rates when premeiotic events are involved. Environ Mutagen 1, 37-43

Engels WR (1983) The P family of transposable elements in Drosophila. Ann Rev Genet 17, 315-344

Engels WR (1988) P elements in Drosophila. In : Mobile DNA (Berg D, Howe M, eds) ASM Publications, Washington, DC, 437-484

Falconer DS (1981) Introduction to Quantitative Genetics. Longman, London

Finnegan DJ (1989) The I factor and I-R hybrid dysgenesis in Drosophila melanogaster. In : Mobile DNA (Berg D, Howe M, eds) ASM Publications, Washington, DC, 503-518

Fitzpatrick BJ, Sved JA (1986) High levels of fitness modifiers induced by hybrid dysgenesis in Drosophila melanogaster. Genet Res 48, 89-94

Gvozdev VA, Belyaeva ES, Illyin YV, Amosova IS, Kaidanov LZ (1981) Selection and transposition of mobile dispersed genes in Drosophila melanogaster. Cold Spring Harbor Symp Quant Biol 45, 673-685

Higuet D (1986) Disruptive selection on body weight in Drosophila melanogaster. Evolution 40 (2), 272-278

Hill WG (1977) Variation in response to selection. In : Proc Int Conf Quant Genet (Pollack E, Kempthorne O, Bailey TB, eds) Iowa State University Press, Ames, IA, 343-365

Jackson MS, Black DM, Dover GA (1988) Amplification of KP elements associated with the repression of hybrid dysgenesis in Drosophila melanogaster. Genetics 120, $1003-1013$ 
Junaković N, Caneva R, Ballario P (1984) Genomic distribution of copia-like element in laboratory stocks of Drosophila melanogaster. Chromosoma 90, 378-382 Kidwell MG, Kimura K, Black DM (1988) Evolution of hybrid dysgenesis potential following $\mathrm{P}$ element contamination in Drosophila melanogaster. Genetics 119, 815828

Kidwell MG, Kidwell JF, Sved JA (1977) Hybrid dysgenesis in Drosophila melanogaster. A syndrome of aberrant traits including mutation, sterility, and male recombination. Genetics $86,813-833$

Kocur GJ, Drier EA, Simmons MJ (1986) Sterility and hypermutability in the PM system of hybrid dysgenesis in Drosophila melanogaster. Genetics 114, 1147-1163

Lai C, Mackay TFC (1990) Hybrid dysgenesis-induced quantitative variation on the X chromosome of Drosophila melanogaster. Genetics 124, 627-636

Mackay TFC (1984) Jumping genes meet abdominal bristles : hybrid dysgenesisinduced quantitative variation in Drosophila melanogaster. Genet Res 44, 231-237 Mackay TFC (1985) Transposable element-induced response to artificial selection in Drosophila melanogaster. Genetics 111, 351-374

Mackay TFC (1986) Transposable elements induced fitness mutations in Drosophila melanogaster. Genet Res 48, 77-87

Mackay TFC (1989) Transposable elements and fitness in Drosophila. Genome 31, 284-295

Morton RA, Hall SC (1985) Response of dysgenic and non-dysgenic populations to malathion exposure. Drosophila Inf Serv 61, 126-128

O'Hare K, Rubin GM (1983) Structure of P transposable elements and their sites of insertion and excision in the Drosophila melanogaster genome. Cell 34, 25-35

Pardue ML, Gall JG (1975) Nucleic acid hybridization to the DNA of cytological preparation. In : Methods in Cell Biology (Prescott DM, ed) Academic Press, NY, $1-16$

Pélisson A, Brégliano JC (1987) Evidence for rapid limitation of the I element copy number in a genome submitted to several generations of IR hybrid dysgenesis in Drosophila melanogaster. Mol Gen Genet 207, 306-313

Picard G (1976) Non-Mendelian female sterility in Drosophila melanogaster : hereditary transmission of I factor. Genetics 83, 107-123

Pignatelli PM, Mackay TFC (1989) Hybrid dysgenesis-induced response to selection in Drosophila melanogaster. Genet Res 54, 183-195

Robertson HM, Engels WR (1989) Modified P elements that mimic the P cytotype in Drosophila melanogaster. Genetics 123, 815-824

Shrimpton AE, Mackay TFC, Leigh Brown AJ (1990) Transposable elementinduced response to artificial selection in Drosophila melanogaster : molecular analysis of selection lines. Genetics $125,803-811$

Simmons GM (1987) Sterility-mutability correlation. Genet Res 50, 73-76 Strobel E, Dunsmuir P, Rubin GM (1979) Polymorphism in the chromosomal locations of the 412, copia and 297 dispersed repeated gene families in Drosophila. Cell 17, 429-439 
Torkamanzehi A, Moran C, Nicholas FW (1988) P-element-induced mutation and quantitative variation in Drosophila melanogaster : lack of enhanced response to selection in lines derived from dysgenic crosses. Genet Res 51, 231-238

Williams JA, Pappu SS, Bell JB (1988) Suppressible P element alleles of the vestigial locus in Drosophila melanogaster. Mol Gen Genet 212, 370-374 